\title{
Higher glucagon-to-insulin ratio is associated with elevated glycated hemoglobin levels in type 2 diabetes patients
}

\author{
Minyoung Lee ${ }^{1}$, Minkyung Kim ${ }^{1}$, Jong Suk Park ${ }^{1,2}$, Sangbae Lee ${ }^{1}$, Jihong You ${ }^{1}$, Chul Woo Ahn, \\ Kyung Rae Kim ${ }^{1}$, and Shinae Kang ${ }^{1,2}$
}

\begin{abstract}
${ }^{1}$ Department of Internal Medicine, Gangnam Severance Hospital, Yonsei University College of Medicine, Seoul; ${ }^{2}$ Severance Institute for Vascular and Metabolic Research, Yonsei University College of Medicine, Seoul, Korea
\end{abstract}

Received: July 23, 2016

Revised : September 29, 2016

Accepted: June 26, 2017

\section{Correspondence to}

Shinae Kang, M.D.

Division of Endocrinology,

Department of Internal Medicine,

Gangnam Severance Hospital,

Yonsei University College of

Medicine, 211 Eonju-ro, Gangnam-gu, Seoul o6273, Korea

Tel: +82-2-2019-3335

Fax: $+82-2-3463-3882$

E-mail: shinae95@yuhs.ac
Background/Aims: The importance of $\alpha$-cell dysfunction in the pathogenesis of type 2 diabetes has re-emerged recently. However, data on whether relative glucagon excess is present in clinical settings are scarce. We aimed to investigate associations between glucagon-to-insulin ratio and various metabolic parameters.

Methods: A total of 451 patients with type 2 diabetes naïve to insulin treatment were recruited. Using glucagon-to-insulin ratio, we divided subjects into quartiles according to both fasting and postprandial glucagon-to-insulin ratios.

Results: The mean age of the subjects was 58 years, with a mean body mass index of $25 \mathrm{~kg} / \mathrm{m}^{2}$. The patients in the highest quartile of glucagon-to-insulin ratio had higher glycated hemoglobin (HbArc) levels. HbArc levels were positively correlated with both fasting and postprandial glucagon-to-insulin ratios. Subjects in the highest quartile of postprandial glucagon-to-insulin ratio were more likely to exhibit uncontrolled hyperglycemia, even after adjusting for confounding factors (odds ratio, 2.730; 95\% confidence interval, 1.236 to 6.028 ; $p$ for trend < 0.01).

Conclusions: Hyperglucagonemia relative to insulin could contribute to uncontrolled hyperglycemia in type 2 diabetes patients.

Keywords: Glucagon; Insulin; Hemoglobin A, glycosylated; Diabetes mellitus, type 2; Hyperglycemia

\section{INTRODUCTION}

Defects in insulin secretion and aggravation of insulin resistance are considered the primary factors affecting diabetes development and progression. However, apart from insulin itself, various other factors may also affect glucose regulation in diabetes $[1,2]$. One of these factors may be the dysregulation of glucagon upon pancreatic $\alpha$-cell dysfunction [3-5]. By enhancing gluconeogenesis in the liver, glucagon levels are elevated upon fasting to prevent hypoglycemia [6-8]. The secretory mechanism of glucagon from $\alpha$-cells has been proposed to be regulated by insulin concentrations from $\beta$-cells, which are located closely to $\alpha$-cells $[9,10]$. From a theoretical view, when insulin secretion increases after meals, glucagon secretion must be suppressed [11-13]. However, this mechanism appears to be dysregulated in diabetic patients who show relatively higher postprandial glucagon levels than normal subjects [14,15]. This suggests that $\alpha$-cell resistance or dysfunction may be present in 
patients with diabetes $[4,5,16]$.

In this aspect, Unger [17] has suggested the 'bihormonal-abnormality' hypothesis in regards to the development of diabetes, stating that both relative or absolute hyperglucagonemia and insulin deficiency may be present in diabetic subjects. Recently, both insulin and glucagon have received attention as critical controllers of blood glucose levels [18-21]. Interestingly, in patients with pancreatic cancer, glucagon-to-insulin ratio after a 75-g oral glucose challenge was independently correlated with glycated hemoglobin (HbAic) levels [22]. These results suggested that relative hyperglucagonemia might influence hyperglycemia in diabetes and that modulating the activity of glucagon might be a promising target for achieving glycemic control in a subgroup of diabetic patients $[23,24]$. Nevertheless, data on increases in glucagon relative to insulin and their associations with other clinical parameters are scarce.

In this study, we evaluated whether increases in glucagon relative to insulin (glucagon-to-insulin ratio) are associated with various metabolic parameters and assessed the contributions of relative hyperglucagonemia on blood glucose control.

\section{METHODS}

\section{Study design and population}

Type 2 diabetes mellitus (DM) patients who visited the outpatient clinic at the endocrinology department of Gangnam Severance Hospital in Seoul, Korea from March 2012 to January 2013 were registered ( $n=533 ; 342$ men, 191 women). The study subjects underwent routine blood tests to assess insulin and glucagon levels both before and 2 hours after a meal. This study was approved by the local Institutional Review Board (IRB approval number: 3-2014-0169). Subjects with gestational diabetes or type $1 \mathrm{DM}$ or who had been treated with insulin were excluded from the study. We divided the study population ( $n=451 ; 308$ men, 143 women) into quartiles of the same number of patients according to both fasting and postprandial glucagon-to-insulin ratios, respectively.

\section{Biochemical measurement}

Plasma glucose was measured by the glucose oxidase method using a 747 Automatic Analyzer (Hitachi, To- kyo, Japan). The levels of total cholesterol, high density lipoprotein cholesterol (HDL-C), triglycerides, and alanine aminotransferase (ALT) were evaluated by an enzymatic colorimetric method (Hitachi 747, Daiichi, Tokyo, Japan). Low density lipoprotein cholesterol content was calculated according to the Friedewald formula [25]. HbA1c levels were measured by high-performance liquid chromatography (Cobas Integra 800, Roche, Mannheim, Germany). Insulin and glucagon levels were measured using a radioimmunoassay method (Roche Diagnostics for insulin; MP Biomedicals, Irvine, CA, USA for glucagon).

\section{Statistical analysis}

Continuous variables are presented as the mean \pm standard deviation (SD) and categorical variables as absolute numbers (percentage). The significance of differences in glucagon-to-insulin ratio quartiles was analyzed using either the one-way analysis of variance, the chi-square test, or Fisher exact test as appropriate. The degree of correlation between metabolic parameters and glucagon-to-insulin ratio was presented by Pearson correlation coefficient $(r)$. Independent predictors of gluca gon-to-insulin ratio were assessed by multiple stepwise linear regression analyses and logistic regression models were used to determine the odds ratio (OR) of the covariates. All statistical analyses were performed using SPSS version 20.0 (IBM Co., Armonk, NY, USA), and p values $<0.05$ were considered statistically significant.

\section{Ethical standard}

This human study has been reviewed by the appropriate ethics committee and has therefore been performed in accordance with the ethical standards stipulated in the 1964 Declaration of Helsinki and its following amendments.

\section{Human and animal rights disclosure}

All procedures followed were in accordance with the ethical standards of the responsible committee on human experimentation (institutional and national) and with the Helsinki Declaration of 1975, as revised in 2008. 


\section{RESULTS}

\section{Clinical and biochemical characteristics of the study population}

The mean age of the whole study population was $57.7 \pm$ 12.7 years, and the mean duration of diabetes was $8.7 \pm$ 7.8 years. The mean $\mathrm{HbArc}$ level was $6.96 \% \pm 1.20 \%(52.53$ $\pm 13.13 \mathrm{mmol} / \mathrm{mol}$ ), and the mean body mass index (BMI) was $24.98 \pm 3.29 \mathrm{~kg} / \mathrm{m}^{2}$. Patients in the highest quartiles of both fasting and postprandial glucagon-to-insulin ratios had the highest HbAic levels $(7.19 \% \pm 1.47 \%, p=$ 0.02 for fasting; and $7.28 \% \pm 1.57 \%, p<0.01$ for postprandial glucagon-to-insulin ratio, respectively) and tended to have the longest duration of diabetes $(10.0 \pm 8.1$ years, $p=0.07$ for fasting; and $11.0 \pm 9.2$ years, $p<0.01$ for postprandial glucagon-to-insulin ratio, respectively). These patients also had lower BMI and ALT levels, as well as a higher HDL-C levels, than the other groups (Tables 1 and 2).

\section{Association between metabolic parameters and glucagon-to-insulin ratio}

Correlations between metabolic parameters and fasting or postprandial glucagon-to-insulin ratio were analyzed. Both fasting and postprandial glucose, HbAic and HDL-C levels were positively correlated with fasting glucagon-to-insulin ratio, whereas BMI, triglycerides, and ALT levels showed negative correlations. Duration of diabetes, $\mathrm{HbA1c}$, and HDL-C were positively correlated with postprandial glucagon-to-insulin ratio; BMI, triglycerides, and ALT showed a negative correlation with postprandial glucagon-to-insulin ratio (Table 3).

\section{Independent factors associated with fasting and postprandial glucagon-to-insulin ratios}

We analyzed independent factors associated with both fasting and postprandial glucagon-to-insulin ratios. HbAlc, BMI, and ALT were independent factors associated with fasting glucagon-to-insulin ratio. The postprandial glucagon-to-insulin ratio was significantly and independently associated with HbA1c, duration of diabetes, BMI, and ALT. In both fasting and postprandial states, elevation of HbArc levels was independently associated with higher fasting and postprandial glucagon-to-insulin ratios (regression coefficient $=1.92$, standardized error $=0.43, p<0.01$ for fasting; and regression coefficient $=0.38$, standardized error $=0.11, p<0.01$ for postprandial glucagon-to-insulin ratio) (Table 4).

\section{Association of glucagon-to-insulin ratio with the risk of uncontrolled blood glucose}

To assess the risk of uncontrolled blood glucose levels with respect to glucagon-to-insulin ratio, we performed multiple logistic regression analysis. After adjusting for age, sex, BMI, HDL-C, and ALT, subjects in the highest quartile of postprandial glucagon-to-insulin ratio were 3.7-fold more likely to have uncontrolled diabetes, defined by $\mathrm{HbArc} \geq 7.5 \%(58.5 \mathrm{mmol} / \mathrm{mol})$ (OR, 3.681; 95\% confidence interval [CI], 1.752 to 7.736; $p$ for trend < 0.01). Moreover, subjects in the highest quartile of postprandial glucagon-to-insulin ratio were 2.7-fold more likely to have a higher $\mathrm{HbAlc} \mathrm{level,} \mathrm{even} \mathrm{after} \mathrm{further} \mathrm{adjusting}$ for the duration of diabetes and the use of metformin, sulfonylurea, and dipeptidyl peptidase-4 inhibitor (DPP4 I) (OR, 2.730; 95\% CI, 1.236 to 6.028; p for trend < 0.01) (Table 5). In a model adjusting for age, sex, BMI, HDL-C, ALT, duration of diabetes, and use of metformin, sulfonylurea, and DPP-4 I, ORs for uncontrolled diabetes increased gradually with higher quartiles of postprandial glucagon-to-insulin ratio (OR, 0.739; 95\% CI, 0.321 to 1.701 for Quartile 2; OR, 2.041; 95\% CI, 0.946 to 4.405 for Quartile 3; and OR, 2.730; 95\% CI, 1.236 to 6.028 for Quartile 4, respectively) (Table 5, Fig. 1).

\section{DISCUSSION}

In this study, we found that patients with a higher glucagon-to-insulin ratio upon fasting or in a postprandial state exhibit worse blood glucose control (i.e., higher HbArc levels). Both fasting and postprandial glucagon-to-insulin ratios were found to be positively correlated with $\mathrm{HbA1c}$ and HDL-C levels, whereas they were negatively correlated with ALT. Interestingly, ORs for higher HbAic levels increased gradually with increasing quartiles of postprandial glucagon-to-insulin ratio, demonstrating that glucagon-to-insulin ratio reflects persistent, but gradual, degrees of glycemic control across the whole DM population, rather than there being an abrupt cut-off value of glucagon that indicates glycemic control in an all-or-none fashion. Our results suggest that an increased level of glucagon, relative to 


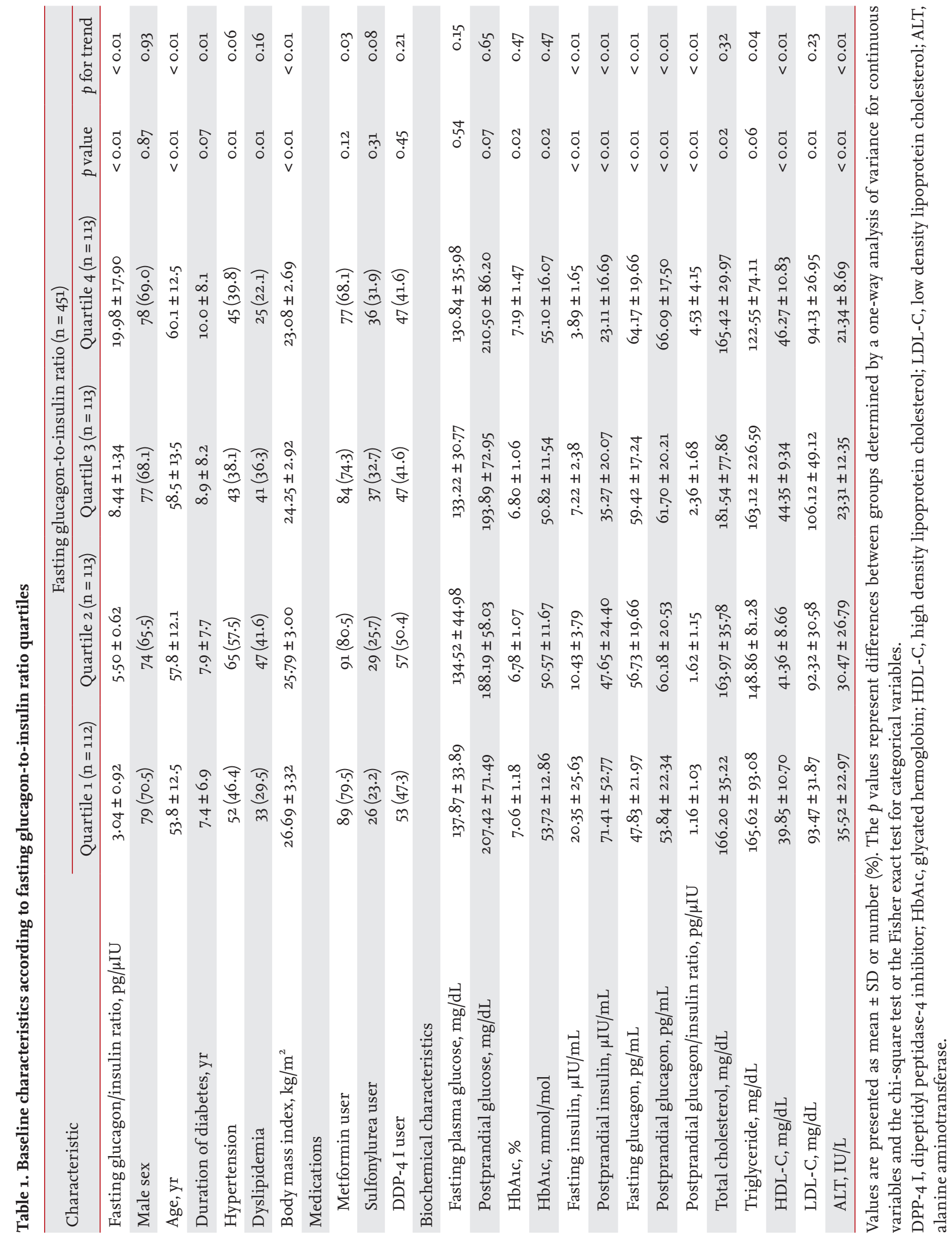




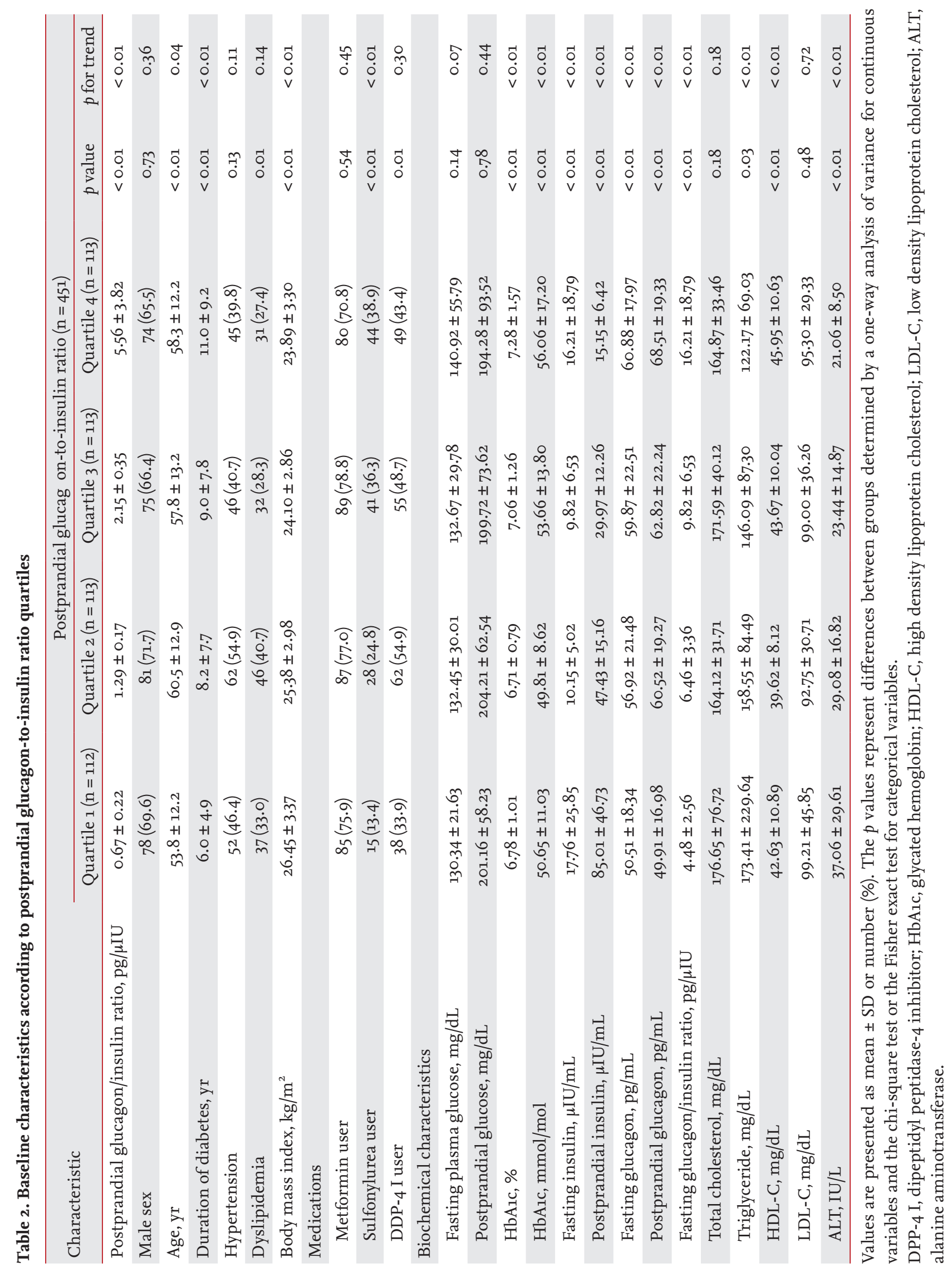


Table 3. Associations between metabolic parameters and glucagon-to-insulin ratio

\begin{tabular}{|c|c|c|c|c|}
\hline \multirow{2}{*}{ Variable } & \multicolumn{2}{|c|}{ Fasting } & \multicolumn{2}{|c|}{ Postprandial } \\
\hline & $r$ & $p$ value & $r$ & $p$ value \\
\hline Age, yr & 0.03 & 0.55 & 0.04 & 0.43 \\
\hline Duration of diabetes, yr & 0.06 & 0.24 & 0.11 & 0.02 \\
\hline Body mass index, $\mathrm{kg} / \mathrm{m}^{2}$ & -0.29 & $<0.01$ & -0.22 & $<0.01$ \\
\hline Fasting plasma glucose, mg/dL & 0.15 & $<0.01$ & 0.07 & 0.12 \\
\hline Postprandial glucose, mg/dL & 0.12 & 0.01 & -0.05 & 0.27 \\
\hline HbAic, \% & 0.20 & $<0.01$ & 0.15 & $<0.01$ \\
\hline Total cholesterol, mg/dL & 0.00 & 0.96 & -0.04 & 0.40 \\
\hline Triglyceride, mg/dL & -0.10 & 0.03 & -0.10 & 0.04 \\
\hline HDL-C, mg/dL & 0.12 & 0.01 & 0.13 & 0.01 \\
\hline LDL-C, mg/dL & 0.04 & 0.42 & -0.01 & 0.83 \\
\hline ALT, IU/L & -0.16 & $<0.01$ & -0.18 & $<0.01$ \\
\hline
\end{tabular}

Values are presented as Pearson's correlation coefficient $(r)$. A $p<0.05$ was regarded as statistically significant.

HbAic, glycated hemoglobin; HDL-C, high density lipoprotein cholesterol; LDL-C, low density lipoprotein cholesterol; ALT, alanine aminotransferase.

Table 4. Independent factors associated with glucagon-to-insulin ratio

\begin{tabular}{|c|c|c|c|c|c|c|c|c|}
\hline \multirow{3}{*}{ Variable } & \multicolumn{8}{|c|}{ Multi-variate regression analysis } \\
\hline & \multicolumn{4}{|c|}{ Fasting } & \multicolumn{4}{|c|}{ Postprandial } \\
\hline & $\begin{array}{r}\text { Regression } \\
\text { coefficient }\end{array}$ & SE & $p$ value & $R^{2}$ & $\begin{array}{r}\text { Regression } \\
\text { coefficient }\end{array}$ & SE & $p$ value & $R^{2}$ \\
\hline Duration of diabetes, yr & 0.03 & 0.07 & 0.68 & 0.14 & 0.03 & 0.02 & 0.05 & 0.12 \\
\hline Body mass index, $\mathrm{kg} / \mathrm{m}^{2}$ & -0.79 & 0.16 & $<0.01$ & 0.14 & -0.13 & 0.04 & $<0.01$ & 0.12 \\
\hline HbAic, \% & 1.92 & 0.43 & $<0.01$ & 0.14 & 0.38 & 0.11 & $<0.01$ & 0.12 \\
\hline HDL-C, mg/dL & 0.08 & 0.05 & 0.12 & 0.14 & 0.02 & 0.01 & 0.06 & 0.12 \\
\hline ALT, IU/L & -0.06 & 0.03 & 0.02 & 0.14 & -0.02 & 0.01 & 0.01 & 0.12 \\
\hline Metformin medication & -1.39 & 1.28 & 0.28 & 0.14 & -0.57 & 0.31 & 0.07 & 0.12 \\
\hline Sulfonylurea medication & 1.23 & 1.23 & 0.32 & 0.14 & 0.24 & 0.30 & 0.43 & 0.12 \\
\hline DPP-4 I medication & -1.04 & 1.10 & 0.34 & 0.14 & -0.38 & 0.27 & 0.16 & 0.12 \\
\hline
\end{tabular}

Values are presented as regression coefficient and standard error. A $p<0.05$ was regarded as statistically significant.

SE, standard error; HbAic, glycated hemoglobin; HDL-C, high density lipoprotein cholesterol; ALT, alanine aminotransferase; DPP-4 I, dipeptidyl peptidase-4 inhibitor.

insulin, is closely associated with poor glycemic control.

Our study highlighted glucagon excess relative to insulin in a postprandial state as being associated with poor glycemic control. Previously, several studies suggested that absolute or relative hyperglucagonemia may be a cause of poor glycemic control in subjects with impaired glucose tolerance or diabetes [13,16,26-30]. However, most of these studies were performed in a small number of subjects, and no study has explored what features are associated with relative glucagon excess
$[11,16,28,31,32]$. Overcoming these limitations, we have demonstrated in a relatively large number of subjects ( $\mathrm{n}$ $=451$ ) that relative glucagon excess is associated with various metabolic parameters in clinical practice.

We initially hypothesized that subjects with relative glucagon excess might be associated with poor glycemic control, together with both insulin resistance and worse metabolic parameters [11,15,33,34]. Interestingly, we found that subjects with higher glucagon-to-insulin ratio had lower BMI and higher HDL despite poor 
Table 5. Odds ratio for uncontrolled hyperglycemia (HbA1c $\geq 7 \cdot 5 \%)$.

\begin{tabular}{|c|c|c|c|c|c|}
\hline Variable & Quartile $1(n=112)$ & Quartile $2(n=113)$ & Quartile $3(n=113)$ & Quartile $4(n=113)$ & $p$ for trend \\
\hline \multicolumn{6}{|c|}{ Fasting glucagon-to-insulin ratio $(\mathrm{n}=451)$} \\
\hline Model $1^{\mathrm{a}}$ & 1.00 (reference) & $0.451(0.230-0.885)$ & $0.552(0.289-1.055)$ & $1.080(0.602-1.939)$ & 0.65 \\
\hline Model $2^{b}$ & 1.00 (reference) & $0.470(0.239-0.927)$ & $0.582(0.303-1.117)$ & $1.166(0.642-2.119)$ & 0.49 \\
\hline Model $3^{c}$ & 1.00 (reference) & $0.468(0.232-0.944)$ & $0.734(0.366-1.474)$ & $1.539(0.772-3.070)$ & 0.13 \\
\hline Model $4^{\mathrm{d}}$ & 1.00 (reference) & $0.388(0.184-0.818)$ & $0.566(0.270-1.188)$ & $1.317(0.631-2.749)$ & 0.33 \\
\hline \multicolumn{6}{|c|}{ Postprandial glucagon-to-insulin ratio $(n=451)$} \\
\hline Model $1^{\mathrm{a}}$ & 1.00 (reference) & $0.799(0.381-1.678)$ & $1.888(0.981-3.633)$ & $2.248(1.179-4.283)$ & $<0.01$ \\
\hline Model $2^{b}$ & 1.00 (reference) & $0.874(0.411-1.855)$ & $1.991(1.029-3.856)$ & $2.391(1.245-4.592)$ & $<0.01$ \\
\hline Model $3^{c}$ & 1.00 (reference) & $0.902(0.407-1.999)$ & $2.902(1.394-6.042)$ & $3.681\left(1.75^{2}-7.736\right)$ & $<0.01$ \\
\hline Model $4^{\mathrm{d}}$ & 1.00 (reference) & $0.739(0.321-1.701)$ & $2.041(0.946-4.405)$ & $2.730(1.236-6.028)$ & $<0.01$ \\
\hline
\end{tabular}

Values are presented as odds ratios with the lowest quartile group of glucagon/insulin ratio as a reference. A $p$ for trend $<0.05$ was regarded as statistically significant.

HbA1c, glycated hemoglobin.

${ }^{\mathrm{a}}$ Model 1 , not adjusted.

${ }^{\mathrm{b}}$ Model 2, adjusted for age and sex.

${ }^{\mathrm{c}}$ Model 3, adjusted for age, sex, body mass index (BMI), high density lipoprotein cholesterol (HDL-C), and alanine aminotransferase (ALT).

${ }^{\mathrm{d}}$ Model 4, adjusted for age, sex, BMI, HDL-C, ALT, duration of diabetes, metformin medication, sulfonylurea medication, and dipeptidyl peptidase-4 inhibitor medication.

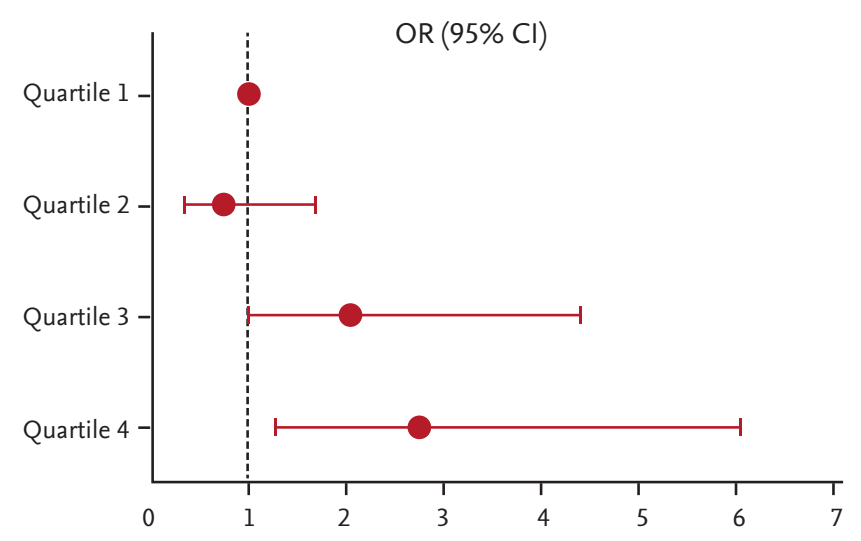

Figure 1. Odds ratio for glycated hemoglobin $\geq 7.5 \%$ according to postprandial glucagon-to-insulin ratio quartiles. Logistic regression was used for calculating odds ratios (ORs) with $95 \%$ confidence intervals (CIs). The reference group comprised patients in the lowest quartile of postprandial glucagon-to-insulin ratio (Quartile 1). Adjusted for age, sex, body mass index, high density lipoprotein cholesterol, alanine aminotransferase, duration of diabetes, and metformin, sulfonylurea, and dipeptidyl peptidase-4 inhibitor use.

glycemic control (higher HbA1c levels). The characteristics of our study group seem to be in line with those of non-obese Asian diabetic patients with islet dysfunction $[30,35]$. A previous study showed that lean patients with type 2 diabetes can exhibit better lipid profile than obese patients, even though the lean patients have more uncontrolled hyperglycemia [36]. Lower BMI is normally accompanied with better metabolic profile [37]. However, in non-obese patients with type 2 diabetes, BMI with insulin resistance is not the major determinant of glycemic control [38]. Thus, there could have been a discrepancy between metabolic profiles and glycemic control in our study population [36]. In these individuals, $\beta$-cell dysfunction, reflected as insulin deficiency, rather than insulin resistance, may be the dominant factor for uncontrolled hyperglycemia [38]. In addition to this, we assume that not only $\beta$-cell hypofunction but also relative $\alpha$-cell hyperfunction may contribute to poor glycemic control in this study population. Several papers have found glucagon excess to be an independent pathogenesis from insulin resistance in type 2 diabetes [13,39,40], and hyperglucagonemia has been continually detected in diabetic patients without obesity [31]. Additionally, a previous study found decreased $\beta$-cell and increased $\alpha$-cell mass in pancreatic islets of Korean type 2 diabetes patients with a BMI less than $25 \mathrm{~kg} / \mathrm{m}^{2}$ [30]. In the present study, we noted that glucagon-to-insulin ratio exhibited an increasing tendency as the duration of di- 
abetes became longer. This implies that overall islet cell dysfunction becomes worse as type 2 diabetes progresses. Therefore, our study suggests that, in patients with lower BMI and long-standing type 2 diabetes, strategies to suppress glucagon excess together with promoting insulin secretion may be helpful.

The relationship between glucagon-to-insulin ratio and $\mathrm{HbA1c}$ has been rarely studied. Jin et al. [22] showed a linear association between glucagon-to-insulin ratio and HbA1c in subjects with pancreatic cancer, a tendency which was similar to that in our study of data for type 2 diabetic subjects. In our study, we further demonstrated that glucagon-to-insulin ratio is a significant determinant of glycemic control. The OR of postprandial glucagon-to-insulin ratio followed a significantly increasing trend in analysis of $p$ for trend. Also, interestingly, the general shape of ORs followed a J-shape, with postprandial glucagon-to-insulin ratios in quartile $2<$ quartile 1 and those in quartiles 3 and $4>$ quartile 1 . The possible reasons for this J-shaped association between the glycemic control and the glucagon-to-insulin ratio could be the result of unique clinical characteristics in quartile 2, such as higher age and higher DPP-4 I use, compared to the other quartiles.

This study is not without limitations. Most of the study subjects were from urban areas and had generally well-controlled glucose levels, which may not represent the entire diabetic population. This study also has the general limitation of being cross-sectional study, and thus, it cannot demonstrate whether there is a causal relationship between glucose control and glucagon-to-insulin ratio. Postprandial glucagon and insulin in this study were not measured after oral glucose tolerance test but after a normal meal, which means calorie and nutrient intakes may have varied from subject to subject. In addition, study subjects with various medications, such as metformin, sulfonylurea, and DPP-4 I, could be another limitation as well, because these medications might affect serum levels of insulin and glucagon. However, statistical significance was still prominent even after adjusting for all three medications, and this may also strengthen our main findings. Conversely, our data may reflect "everyday" changes in glucagon, insulin, and glucose in actual clinical practice.

In summary, type 2 diabetes patients with higher glucagon-to-insulin ratios, especially in a postprandial state, were more likely to show uncontrolled hyperglycemia. Accordingly, we suggest that different treatment approaches may be needed for subjects with relatively lower BMI, less insulin resistance, and dysregulated glucagon levels, compared to patients with higher BMI and more insulin resistance. Instead of concentrating on improvements in insulin resistance, a strategy to suppress glucagon together with increasing insulin secretion may be another key therapeutic option for treating type 2 diabetic patients in the future. Understanding the diverse pathogenesis of hyperglycemia may help to personalize treatment strategies in type 2 diabetes. Larger studies to investigate the effect of glucagon together with the action of insulin are warranted.

\section{KEY MESSAGE}

1. Hyperglucagonemia relative to insulin could contribute to uncontrolled hyperglycemia in type 2 diabetes patients.

2. A strategy to suppress glucagon together with increasing insulin secretion may be another key therapeutic option for treating type 2 diabetic patients with lower body mass index and less insulin resistance.

\section{Conflict of interest}

No potential conflict of interest relevant to this article was reported.

\section{Acknowledgments}

This research was supported by a grant from the Korea Health Technology R\&D Project through the Korea Health Industry Development Institute(KHIDI), funded by the Ministry of Health and Welfare, Republic of Korea (grant number: $\mathrm{HI}_{14} \mathrm{Co} 336$ ). The authors are grateful to Dr. Lee and Ms. Hong (the Biostatistics Collaboration Units of Yonsei University College of Medicine) for their advice on the statistical analyses.

\section{REFERENCES}

1. Defronzo RA. Banting lecture. From the triumvirate to the ominous octet: a new paradigm for the treatment of 
type 2 diabetes mellitus. Diabetes 2009;58:773-795.

2. Fonseca VA. Defining and characterizing the progression of type 2 diabetes. Diabetes Care 2009;32 Suppl 2:S151-S156.

3. Edgerton DS, Cherrington AD. Glucagon as a critical factor in the pathology of diabetes. Diabetes 2011;60:377-380.

4. Li XC, Zhuo JL. Current insights and new perspectives on the roles of hyperglucagonemia in non-insulin-dependent type 2 diabetes. Curr Hypertens Rep 2013;15:522-530.

5. Quesada I, Tuduri E, Ripoll C, Nadal A. Physiology of the pancreatic alpha-cell and glucagon secretion: role in glucose homeostasis and diabetes. J Endocrinol 2008;199:5-19.

6. Liljenquist JE, Mueller GL, Cherrington AD, et al. Evidence for an important role of glucagon in the regulation of hepatic glucose production in normal man. J Clin Invest 1977;59:369-374.

7. Ramnanan CJ, Edgerton DS, Kraft G, Cherrington AD. Physiologic action of glucagon on liver glucose metabolism. Diabetes Obes Metab 2011;13 Suppl 1:118-125.

8. Tappy L. Regulation of hepatic glucose production in healthy subjects and patients with non-insulin-dependent diabetes mellitus. Diabete Metab 1995;21:233-240.

9. Franklin I, Gromada J, Gjinovci A, Theander S, Wollheim CB. Beta-cell secretory products activate alpha-cell ATP-dependent potassium channels to inhibit glucagon release. Diabetes 2005:54:1808-1815.

10. Leung YM, Ahmed I, Sheu L, et al. Insulin regulates islet alpha-cell function by reducing KATP channel sensitivity to adenosine 5'-triphosphate inhibition. Endocrinology 2006;147:2155-2162.

11. Ahren B, Larsson H. Impaired glucose tolerance (IGT) is associated with reduced insulin-induced suppression of glucagon concentrations. Diabetologia 2001;44:1998-2003.

12. Shah P, Basu A, Basu R, Rizza R. Impact of lack of suppression of glucagon on glucose tolerance in humans. Am J Physiol 1999;277:E283-E290.

13. Shah P, Vella A, Basu A, Basu R, Schwenk WF, Rizza RA. Lack of suppression of glucagon contributes to postprandial hyperglycemia in subjects with type 2 diabetes mellitus. J Clin Endocrinol Metab 2000;85:4053-4059.

14. Ipp E. Impaired glucose tolerance: the irrepressible alpha-cell? Diabetes Care 2000;23:569-570.

15. Larsson H, Ahren B. Islet dysfunction in insulin resistance involves impaired insulin secretion and increased glucagon secretion in postmenopausal women with impaired glucose tolerance. Diabetes Care 2000;23:650-657.
16. Ahren B. Beta- and alpha-cell dysfunction in subjects developing impaired glucose tolerance: outcome of a 12-year prospective study in postmenopausal Caucasian women. Diabetes 2009;58:726-731.

17. Unger RH. Role of glucagon in the pathogenesis of diabetes: the status of the controversy. Metabolism 1978;27:1691-1709.

18. Charron MJ, Vuguin PM. Lack of glucagon receptor signaling and its implications beyond glucose homeostasis. J Endocrinol 2015;224:R123-R130.

19. Cho YM, Merchant CE, Kieffer TJ. Targeting the glucagon receptor family for diabetes and obesity therapy. Pharmacol Ther 2012;135:247-278.

20. Dunning BE, Foley JE, Ahren B. Alpha cell function in health and disease: influence of glucagon-like peptide-1. Diabetologia 2005;48:1700-1713.

21. Rohrer S, Menge BA, Gruber L, et al. Impaired crosstalk between pulsatile insulin and glucagon secretion in prediabetic individuals. J Clin Endocrinol Metab 2012;97:E791-E795.

22. Jin SM, Choi SH, Choi DW, et al. Glucagon/insulin ratio in preoperative screening before pancreatic surgery: correlation with hemoglobin $\mathrm{Al}_{1} \mathrm{C}$ in subjects with and without pancreatic cancer. Endocrine 2014;47:493-499.

23. Moon JS, Won KC. Pancreatic $\alpha$-cell dysfunction in type 2 diabetes: old kids on the block. Diabetes Metab J 2015;39:1-9.

24. Rivera N, Everett-Grueter CA, Edgerton DS, et al. A novel glucagon receptor antagonist, NNC 25-0926, blunts hepatic glucose production in the conscious dog. J Pharmacol Exp Ther 2007;321:743-752.

25. Friedewald WT, Levy RI, Fredrickson DS. Estimation of the concentration of low-density lipoprotein cholesterol in plasma, without use of the preparative ultracentrifuge. Clin Chem 1972;18:499-502.

26. Abdul-Ghani M, DeFronzo RA. Fasting hyperglycemia impairs glucose- but not insulin-mediated suppression of glucagon secretion. J Clin Endocrinol Metab 2007;92:1778-1784.

27. Ahlkvist L, Omar B, Valeur A, Fosgerau K, Ahren B. Defective insulin secretion by chronic glucagon receptor activation in glucose intolerant mice. J Endocrinol 2016;228:171-178.

28. Baron AD, Schaeffer L, Shragg P, Kolterman OG. Role of hyperglucagonemia in maintenance of increased rates of hepatic glucose output in type II diabetics. Diabetes 
1987;36:274-283.

29. Consoli A, Nurjhan N, Capani F, Gerich J. Predominant role of gluconeogenesis in increased hepatic glucose production in NIDDM. Diabetes 1989;38:550-557.

30. Yoon $\mathrm{KH}$, Ko $\mathrm{SH}$, Cho JH, et al. Selective beta-cell loss and alpha-cell expansion in patients with type 2 diabetes mellitus in Korea. J Clin Endocrinol Metab 2003;88:23002308.

31. Reaven GM, Chen YD, Golay A, Swislocki AL, Jaspan JB. Documentation of hyperglucagonemia throughout the day in nonobese and obese patients with noninsulin-dependent diabetes mellitus. J Clin Endocrinol Metab 1987;64:106-110.

32. Umpaichitra V, Bastian W, Taha D, Banerji MA, AvRuskin TW, Castells S. C-peptide and glucagon profiles in minority children with type 2 diabetes mellitus. J Clin Endocrinol Metab 2001;86:1605-1609.

33. Ferrannini E, Muscelli E, Natali A, et al. Association of fasting glucagon and proinsulin concentrations with insulin resistance. Diabetologia 2007;50:2342-2347.

34. Liu Z, Kim W, Chen Z, et al. Insulin and glucagon regulate pancreatic $\alpha$-cell proliferation. PLoS One 2011;6:e16096.
35. Ohn JH, Kwak SH, Cho YM, et al. 10-Year trajectory of $\beta$-cell function and insulin sensitivity in the development of type 2 diabetes: a community-based prospective cohort study. Lancet Diabetes Endocrinol 2016;4:27-34.

36. Mohan V, Vijayaprabha R, Rema M, et al. Clinical profile of lean NIDDM in South India. Diabetes Res Clin Pract 1997;38:101-108.

37. Chang SA, Kim HS, Yoon KH, et al. Body mass index is the most important determining factor for the degree of insulin resistance in non-obese type 2 diabetic patients in Korea. Metabolism 2004;53:142-146.

38. Kim DJ, Lee MS, Kim KW, Lee MK. Insulin secretory dysfunction and insulin resistance in the pathogenesis of Korean type 2 diabetes mellitus. Metabolism 2001;50:590-593.

39. Bessho M, Murase-Mishiba Y, Tsutsumi C, et al. Glycaemic instability correlates with a hyperglucagonaemic response in patients with type 1 diabetes without residual beta-cell function. Diabetes Res Clin Pract 2013;102:e38-e40.

40. Dinneen S, Alzaid A, Turk D, Rizza R. Failure of glucagon suppression contributes to postprandial hyperglycaemia in IDDM. Diabetologia 1995;38:337-343. 